\title{
Um olhar para a alfabetização a partir dos exames nacionais
}

\author{
Maria Teresa Esteban*, Célia Cláudia Wolf** \\ *UFF/CNpq - Brasil, **FME/Niterói - Brasil
}

\begin{abstract}
Resumo
O estudo se debruça sobre a Provinha Brasil, avaliação em larga escala aplicada aos estudantes brasileiros, para discutir o conceito de alfabetização que mobiliza e a pertinência das práticas pedagógicas que estimula. A pesquisa se realizou no município de Niterói, com análise dos seus resultados nesse exame, de documentos e dados sobre repetência, estabelecendo relações com o cotidiano escolar. Os resultados assinalam: incoerências entre parâmetros usados e discrepâncias entre os desempenhos nos exames nacionais e no processo de escolarização. Nossas conclusões ressaltam uma proposta de avaliação reducionista e fomento de práticas pedagógicas que se entrelaçam a perspectivas classificatória e excludente.
\end{abstract}

Palavras-chave: avaliação externa, cotidiano escolar, aprendizagem, classes populares, diferença

A alfabetização é tema recorrente nos estudos e debates no Brasil especialmente pela reduzida capacidade de uso da leitura e da escrita por grande parte dos estudantes brasileiros. Muitas têm sido as propostas oficiais para enfrentar essa insuficiência de nosso sistema educacional. Dentre elas, se apresenta a avaliação em larga escala, intensificada nos últimos anos com a finalidade de monitorar a educação através de exames externos, promovidos pelas diversas esferas públicas.

O sistema de avaliação abrange os diferentes níveis de ensino e se apresenta em estreita vinculação com a conquista da qualidade de educação almejada. Os três primeiros anos do ensino fundamental são considerados o período em que a alfabetização se realiza, sendo uma das principais metas da educação no Brasil que todas as crianças se alfabetizem até os oito anos de idade. A esse período da escolarização se destinam dois exames nacionais: a Provinha Brasil e a Avaliação Nacional da Alfabetização.

Esse contexto demarca as pesquisas ${ }^{1}$ que sustentam este artigo, cujo foco são as relações entre os resultados da Provinha Brasil, as práticas escolares cotidianas e as aprendizagens infantis. $\mathrm{O}$ diálogo entre essas pesquisas, que associam procedimentos quantitativos e

\footnotetext{
1 As pesquisas a que nos referimos são: A reconstrução de práticas de avaliação numa perspectiva emancipatória no cotidiano escolar, coordenado por Maria Teresa Esteban, com bolsa do $\mathrm{CNPq}$, e Provinha Brasil no Município de Niterói: uma discussão sobre avaliação e concepções de aprendizagem na alfabetização, realizado por Célia Wolf.
}

qualitativos, nos permite problematizar os conceitos de alfabetização e de avaliação que esse exame mobiliza e a pertinência, para a aprendizagem das crianças das classes populares, das práticas pedagógicas que estimula. Trazemos à tona um retrato obtido a partir da análise dos resultados deste exame na cidade de Niterói, município pertencente à região metropolitana do Rio de Janeiro, um dos principais Estados brasileiros, e os discutimos considerando dados sobre reprovação escolar no mesmo município, documentos oficiais que acompanham os exames e questões observadas em uma escola de sua rede pública de educação.

\section{Alfabetização: uma palavra, muitos conceitos}

A Provinha Brasil é uma avaliação externa em larga escala, proposta como avaliação diagnóstica do nível de alfabetização das crianças matriculadas no segundo ano do ensino fundamental das escolas públicas brasileiras, com foco em sua capacidade de leitura (Instituto Nacional de Estudos e Pesquisas Educacionais Anísio Teixeira [INEP], s/d). Segundo a Matriz de Referência da Provinha, os resultados são classificados em 5 níveis: o nível 1 representa $o$ domínio das capacidades mais elementares do processo de apropriação da leitura e o nível 5 representa o desempenho mais avançado. Essa avaliação teve início em 2008 e desde então ocorre regularmente duas vezes por ano.

Nosso estudo tem como base o acompanhamento dos resultados do município de Niterói, na avaliação de Língua Portuguesa. Como consideramos o período compreendido entre 2008 e 2013, não incorporamos a avaliação das habilidades em Matemática, que só começou a ser aplicada em 2011. Nesse período houve uma ascensão significativa no nível de desempenho no teste, passando do nível 3 em 2008, para o nível máximo de desempenho, o nível 5 em 2013. Entretanto, no mesmo período, os índices de reprovação ao final do $3^{\circ}$ ano do $1^{\circ}$ ciclo se mantiveram praticamente inalterados, tendo, inclusive um ligeiro crescimento.

O ensino Fundamental na Rede Municipal de Niterói está organizado em 4 ciclos, assim constituídos: $1^{\circ}$ ciclo, composto de 3 anos escolares $\left(1^{\circ}, 2^{\circ}\right.$ e $3^{\circ}$ ano), e os 3 ciclos posteriores com dois anos escolares cada. $\mathrm{O}$ divisor de águas entre aprovação e repetência no $3^{\circ}$ ano escolar do I ciclo se faz justamente em função da aprendizagem da leitura/escrita. Se a Rede de Niterói apresentou melhora no desempenho das capacidades de 
leitura na Provinha, o que explica a reprovação dos estudantes? Por qual/quais motivo(s) haveria descompasso entre os resultados da Provinha e os índices de reprovação?

Essas perguntas nos fizeram questionar a relação entre o desempenho aferido pela Provinha Brasil e a aprendizagem da leitura e nos indicaram ser preciso repensar, sobretudo, em que conceito de alfabetização se pauta esse instrumento.

Nesse sentido, encaminhamos uma análise mais profunda dos resultados obtidos desde 2008, enfocando também a relação entre as questões propostas e os descritores a elas correspondentes. Os descritores, também chamados habilidades, compõem a Matriz de Referência, detalhando os aspectos avaliados que se organizam em torno de dois Eixos: apropriação do sistema de escrita e Leitura.

Inicialmente foram mapeados, dentre os descritores propostos na Matriz de Referência de cada ano incluído no trabalho, os que têm recebido maior relevância na composição da Provinha Brasil e como essa seleção pode se refletir no desempenho alcançado pelos alunos. A Provinha Brasil trabalha com 5 eixos de aprendizagens consideradas imprescindíveis para 0 desenvolvimento da alfabetização e do letramento: apropriação do sistema de escrita, compreensão e valorização da cultura escrita, leitura, escrita e desenvolvimento da oralidade. No entanto, as questões se direcionado apenas aos eixos de Leitura e Apropriação do Sistema de Escrita, permeados pelo que os elaboradores chamam de compreensão e valorização da cultura escrita.

Considerando as habilidades destinadas a cada eixo, efetivamente usado na Provinha, na Matriz Conceitual de cada ano, averiguamos uma quantidade maior das habilidades para o eixo de Leitura do que para o outro eixo. No entanto, examinando o quantitativo de questões que foram destinadas a cada descritor ano a ano na Provinha é possível perceber que há maior quantidade de questões ligadas às habilidades de Apropriação do Sistema de Escrita. Mesmo algumas questões ligadas a descritores do eixo de Leitura acabam por se aproximar mais dos processos de decodificação. Visualizando este cenário, teremos ano a ano os seguintes dados:

Tabela 1.

Provinha Brasil $1^{a}$ etapa de 2008 a 2013- Objetivos das questões

\begin{tabular}{lrrrrrr}
\hline ANO/finalidade & $\mathbf{2 0 0 8}$ & $\mathbf{2 0 0 9}$ & $\mathbf{2 0 1 0}$ & $\mathbf{2 0 1 1}$ & $\mathbf{2 ~ 0 1 2}$ & $\mathbf{2 0 1 3}$ \\
\hline $\begin{array}{l}\text { Decodificação } \\
\text { Interpretação de } \\
\text { textos }\end{array}$ & $67 \%$ & $79 \%$ & $79 \%$ & $70 \%$ & $75 \%$ & $70 \%$ \\
\hline
\end{tabular}

Tabela 2.

Provinha Brasil $2^{a}$ etapa de 2008 a 2013-Objetivos das questões

\begin{tabular}{lrrrrrr}
\hline ANO/finalidade & $\mathbf{2 0 0 8}$ & $\mathbf{2 0 0 9}$ & $\mathbf{2 0 1 0}$ & $\mathbf{2 0 1 1}$ & $\mathbf{2 0 1 2}$ & $\mathbf{2 0 1 3}$ \\
\hline Decodificação & $59 \%$ & $75 \%$ & $75 \%$ & $75 \%$ & $60 \%$ & $60 \%$ \\
Interpretação de textos & $41 \%$ & $25 \%$ & $25 \%$ & $25 \%$ & $40 \%$ & $40 \%$ \\
\hline
\end{tabular}

O foco na decodificação se dá especialmente na $1^{\mathrm{a}}$ etapa da Provinha, quando temos em média $70 \%$ das questões ligadas à decodificação. $\mathrm{Na} 2^{\mathrm{a}}$ etapa, pode-se notar que esse parâmetro ainda se conserva e mesmo nos anos em que se encontram percentuais um pouco menores, ainda se percebe em torno de $20 \%$ a mais de questões ligadas à decodificação. Essa tendência propicia, ao nosso ver, um esvaziamento do sentido da leitura como produção de sentido e possibilidade de diálogo entre o leitor e autor.

Notamos que as questões da Provinha mantêm constantemente uma sequência que vai do mais "simples" para o mais "complexo". Processo traduzido na Provinha em questões que abordam conhecimento sobre letra, sílaba, palavra e frase inicialmente, para somente ao final contemplar pequenos textos. Em algumas das questões relacionadas a leitura de textos permanece a mesma sequência hierárquica, à medida que destinam-se inicialmente à localização explicitas de informações, só objetivando alguma inferência na leitura em pouquíssimas questões ao final do teste. Essa composição evidencia um arranjo compatível com a perspectiva mecanicista da alfabetização.

Tal organização se apresenta repetidamente, ano a ano, num instrumento que tem clara intenção de contribuir para o aperfeiçoamento e a reorientação das práticas pedagógicas na escola, buscando ter impacto também na formação docente. Os Cadernos de Orientação da Provinha propõem que:

\footnotetext{
"a leitura e as análises dos instrumentos e dos resultados possam se constituir em uma proveitosa fonte de formação" (para os professores e que) "os gestores tenham mais elementos para o aperfeiçoamento do currículo e para a produção e revisão de políticas, como as de formação dos professores alfabetizadores”.(Brasil, 2009, p. 9 grifo nosso)
}

Torna-se pertinente indagar a possibilidade de haver, no âmbito da política pública, um direcionamento à concepção mecanicista da alfabetização, implícita nos processos destes testes. Mortatti nos ajuda a pensar sobre essa questão quando indica a necessidade de:

\begin{abstract}
"pensar nas políticas públicas para o ensino e a aprendizagem iniciais da leitura e escrita com base no pressuposto óbvio de que decisões de ordem teórico-epistemológica ou técnica são também políticas, ou seja, resultam de escolhas centradas em julgamentos de valor dentre opções também de ordem política, uma vez que a ação governamental reflete escolhas em um quadro de conflito, não havendo, portanto, governos imparciais, pois as escolhas sempre envolverão julgamento de valor, ainda que estejam ancoradas em avaliações técnicas". (Mortatti, 2010 p. 331)
\end{abstract}

A opção conceitual adotada na Provinha Brasil mostra-se relevante para a reflexão sobre as práticas escolares cotidianas e as aprendizagens infantis. Esse exame proposto como avaliação da alfabetização infantil, visa "investigar o desenvolvimento das habilidades relativas à alfabetização e ao letramento" (INEP; s/d) $)^{2}$ e, a partir de 2012 , se relaciona ao Pacto

2 - Disponível em http://portal.inep.gov.br/web/provinhabrasil/provinha-brasil. Consulta realizada em 15 de junho de 2015 . 
Nacional pela Alfabetização na idade certa ${ }^{3}$. Embora a palavra alfabetização seja central nas propostas oficiais, se desmembra o processo em duas etapas, Elevação de desempenho: redução da aprendizagem?

reduzindo o sentido de alfabetização, como se observa_Continuamos a discussão observando o descompasso

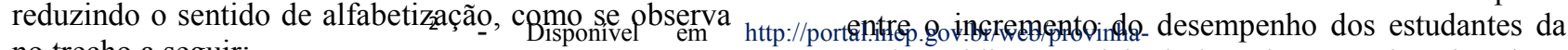
no trecho a seguir: brasil/provinha-brasil. Consulta realizadRedes péblike dmponł́cipal de Educação de Niterói na

“As habilidades constantes na Matriz de Referência estão fundamentadas na concepção de que alfabetização e letramento são processos a serem desenvolvidos de forma complementar e paralela, entendendo-se a alfabetização como o desenvolvimento da compreensão das regras de funcionamento do sistema de escrita alfabética e o letramento como as possibilidades de usos e funções sociais da linguagem escrita, isto é, o processo de inserção e participação dos sujeitos na cultura escrita". ”.(Brasil, 2009, p. 14)

Cabe aqui levantar pontos para a discussão sobre as concepções de alfabetização, de leitura, e posteriormente de avaliação, que pautam a Provinha Brasil. Colocada apenas como a capacidade de compreensão das regras de funcionamento do sistema de escrita alfabética, a alfabetização é conceituada como o domínio do conjunto de sinais convencionais que representam graficamente a língua falada. Introduz-se o termo letramento para indicar as possibilidades de usos e funções sociais da linguagem escrita, isto é, a possibilidade de interpretação deste código.

A essa divisão correspondem os dois sentidos que a leitura assume: mera decodificação de grafemas e fonemas e processo de inserção e participação dos sujeitos na cultura escrita. Esvazia-se o significado de alfabetização, descrita apenas como técnica de decodificação e codificação. Com a ênfase posta na alfabetização, desse modo compreendida, o que se espera das crianças ao final do período avaliado é predominantemente o domínio de conhecimentos mais superficiais, que possam ser mensurados, como exige uma avaliação estandardizada em larga escala. Tomando como exemplo os três primeiros descritores do eixo de leitura - "Ler palavras"; "Ler frases" e "Localizar informação explícita em textos"-, as questões apresentadas na Provinha, a eles articulados, coadunam-se muito mais com as práticas relativas a decifração e decodificação. Portanto, na concepção da Provinha, se aproximam mais do conceito de alfabetização do que do conceito de letramento.

Assim, o processo fomenta, mesmo que indiretamente, o uso dos tradicionais métodos mecanicistas de alfabetização, que favorecem o treinamento das habilidades necessárias ao bom desempenho na Provinha Brasil e tornam mais longo o caminho para a realização da alfabetização como efetiva inclusão das crianças na cultura escrita, como uma ação cultural para a liberdade, em que a leitura do mundo incorpora a leitura da palavra para transformá-lo, conforme propõe Freire.

\footnotetext{
${ }^{3}$ A respeito desse programa do Ministério da Educação, consultar http://pacto.mec.gov.br/
} Provinha, indicando melhora das capacidades de leitura, e as estatísticas de reprovação no mesmo município.

Iniciamos pelos resultados dos segundos testes de cada ano, no Município de Niterói, assim organizados:

Tabela 3.

Resultado geral da Provinha Brasil de Leitura em Niterói

\begin{tabular}{ccccccc}
\hline ANOS & $\mathbf{2 0 0 8}$ & $\mathbf{2 0 0 9}$ & $\mathbf{2 0 1 0}$ & $\mathbf{2 0 1 1}$ & $\mathbf{2 0 1 2}$ & $\mathbf{2 0 1 3}$ \\
\hline $\begin{array}{c}\text { Média } \\
\text { de Acertos }\end{array}$ & 19 & 16 & 19 & 13 & 15 & 16 \\
Nível na Provinha & 4 & 3 & 4 & 3 & 4 & 5 \\
\hline
\end{tabular}

A tabela apresenta as médias de acertos do Município em cada ano, com o equivalente nível alcançado, em cada ano. Há uma variação dos resultados entre os níveis 3 e 4 nos quatro primeiros anos, e em 2013 o desempenho atinge o nível máximo, o nível 5. Esse desempenho tão significativo permitiria esperar que os índices de retenção ao final do $1^{\circ}$ ciclo caíssem drasticamente no ano seguinte da aplicação da Provinha. Poderíamos supor que, especialmente nos dois últimos anos letivos analisados, haveria um melhor rendimento escolar e o nível de aprovação dos alunos subiria progressivamente. Entretanto, não é o que ocorre, como nos mostra o quadro a seguir"

Tabela 4.

Percentuais de Permanência no $3^{\circ}$ ano do $1^{\circ}$ ciclo

\begin{tabular}{ccccccc}
\hline ANOS & $\mathbf{2 0 0 8}$ & $\mathbf{2 0 0 9}$ & $\mathbf{2 0 1 0}$ & $\mathbf{2 0 1 1}$ & $\mathbf{2 0 1 2}$ & $\mathbf{2 0 1 3}$ \\
\hline $\begin{array}{l}\text { Índices de } \\
\text { permanên } \\
\text { cia 3 } 3^{\circ} \text { ano }\end{array}$ & $17,2 \%$ & $17,6 \%$ & $23,6 \%$ & $23,2 \%$ & $21,7 \%$ & $21,2 \%$ \\
\hline
\end{tabular}

O percentual de retenção ${ }^{5}$ na Rede nos anos apresentados manteve-se entre 17 e 23\%. Sua correlação com os resultados da Provinha Brasil no mesmo período de escolarização faz constatar a inexistência de relação direta entre o desempenho no

\footnotetext{
4 Dados obtidos no Portal INEP, disponíveis em http://portal.inep.gov.br. Consulta realizada em 19/12/2014.

5 De acordo com o sistema de progressão no ciclo na Rede de Niterói, os alunos que fizeram a provinha no $2^{\circ}$ ano do $1^{\circ}$ ciclo só poderão ser retidos no ano letivo seguinte, ao cursarem o $3^{\circ}$ ano. Assim, devemos ter em mente que, por exemplo, ao fazer o teste em 2008 no $2^{\circ}$ ano, só em 2009 , o aluno poderá ser retido ou aprovado no $1^{\circ}$ ciclo. Isto quer dizer que os resultados da Provinha num determinado ano, não podem ser comparados com os percentuais de retenção do mesmo ano letivo e sim aos percentuais do ano seguinte, quando os alunos que fizeram a Prova, podem ou não avançar para o próximo ciclo.
} 
teste e o resultado no ciclo, nos índices de retenção ou a efetiva aprendizagem. Daí a necessidade de discutir a associação que os documentos oficiais estabelecem entre desempenho e aprendizagem e de indagar os conhecimentos que estão sendo verificados e estimulados nos testes.

Esse panorama nos oferece pistas suficientes para questionar a contribuição da avaliação em larga escala para que professores e gestores repensem a avaliação de leitura dos alunos e sua validade como instrumento potencializador da prática pedagógica, como sugerem os guias de orientação elaborados pelo INEP. Indagamos se orientar-se por esses níveis pode corroborar uma visão equivocada sobre a aprendizagem dos estudantes e sobre os processos cotidianos que essa avaliação promove.

A análise dos percentuais de acerto em cada uma das questões sugere uma forte tendência de mais acertos naquelas referente a decodificação. Observamos um declínio progressivo do rendimento nas questões dos testes destinadas à interpretação de texto. Distinguindo o resultado em dois blocos, de acordo com os descritores a que se relacionam - decodificação e interpretação -, a classificação nos níveis de 1 a 5 adquire dimensões bem diferentes das observadas até aqui.

Tomando os resultados dos segundos testes dos anos 2012 e 2013, verificamos haver, no primeiro período, 12 questões relacionadas a decodificação e 08 vinculadas a interpretação. No primeiro grupo, os estudantes atingem a média de $88 \%$ de acerto, o que levaria o resultado ao nível 5 , enquanto no outro grupo de questões alcançam a média de $64 \%$ de acerto, o que garantiria o nível 3. No ano de 2013, há 11 questões relacionadas a decodificação e 09 vinculadas a interpretação. Organizada segundo os descritores que norteiam as questões, a média de acertos, no que se refere a decodificação, é de $90 \%$; porém, nas questões relativas a leitura interpretativa, esse percentual cai para $66 \%$. A classificação encontrada nos dois anos é equivalente. A desagregação dos resultados modifica de modo semelhante a classificação dos dois anos tomados aqui como exemplo e evidencia uma diferença expressiva em relação à conclusão proposta pelo INEP sobre as aprendizagens infantis, a partir dos resultados da avaliação e sua classificação em cada um desses níveis.

Considerando essa conclusão, formulada a partir do que se alcançou no Município de Niterói em 2013, indagamos se o nível máximo de desempenho realmente significa o que se lê nos guias de análise de resultado na Provinha:

\footnotetext{
"Neste nível, os alunos demonstram ter alcançado o domínio do sistema de escrita e a compreensão do princípio alfabético, apresentando um excelente desempenho, tendo em vista as habilidades que definem o aluno como alfabetizado e considerando as que são desejáveis para o fim do segundo ano de escolarização. Assim, os alunos que atingiram este nível já avançaram expressivamente no processo de alfabetização e letramento inicial(...)demonstram compreender textos de diferentes gêneros e de complexidade diversa, identificando o assunto principal e localizando informações não evidentes,
}

além de fazerem inferências.".(Brasil, Guia de correção e interpretação de resultados $1^{\circ} \mathrm{s} / 13 \cdot$ teste 1 pag 31)

Mais do que apenas verificar resultados, precisamos nos deter nos objetivo de cada proposta. As aprendizagens das crianças no cotidiano escolar vêm se mostrando distantes da definição citada, não obstante serem compatíveis com a centralidade posta numa alfabetização reduzida aos aspectos mecânicos e superficiais da leitura e da escrita.

\section{Avaliação e cotidiano escolar: retornando à antiga questão.}

A discussão sobre os resultados do município na Provinha Brasil, ao longo de 6 anos, evidencia os limites de uma avaliação em larga escala para apreender e expressar as aprendizagens infantis e para fornecer informações que contribuam para a compreensão dos processos nos quais se constituem, necessária à composição das práticas pedagógicas cotidianas. Esse teste, por suas características, tem pouca capacidade para realizar o diagnóstico a que se propõe, já que se distancia do cotidiano escolar e não pode captar sua tensões, possibilidades e, sobretudo, os conhecimentos, culturas e processos que partilham os estudantes entre si e com os docentes. Essa ausência de informações restringe seu papel na formulação e análise das políticas públicas e das práticas pedagógicas.

A uniformização que uma avaliação nacional em larga escala exige, a homogeneização dos percursos e resultados previstos, a predefinição das interpretações possíveis aos seus resultados e a inevitável construção de níveis nos quais todos devem se enquadrar explicitam os princípios e finalidades classificatórios do processo. Os resultados encontrados no caso em estudo - elevação do índice de desempenho sem redução da reprovação - e sua (aparente?) inconsistência interpelam as reais possibilidades de uso da Provinha Brasil para compreensão dos múltiplos processos de aprendizagem existentes nas salas de aula, pois seu foco está na elevação das médias de desempenho.

O movimento instaurado com a consolidação da avaliação em larga escala reforça a avaliação da aprendizagem como prática eminentemente técnica para a mensuração de desempenho, classificação de sujeitos e tomada de decisão, especialmente sobre como atuar com os que não correspondem à padronização que norteia a dinâmica escolar. Assim, a avaliação se coloca cada dia mais a serviço da produção de índices previamente projetados como desejáveis, ainda que em detrimento de aprendizagens mais densas, como buscamos mostrar neste trabalho. A consolidação dessa concepção de avaliação vai na contramão de uma consistente produção teórica (Hoffmann, 2005; Luckesi, 2005; Saul, 1991, entre outros) que marca a avaliação como processo dialógico, qualitativo, cooperativo, reflexivo, por meio do qual se procura conhecer o sujeito que aprende e seus processos peculiares de aprendizagem, o 
encaminhamento das práticas de ensino, as relações que se estabelecem no processo aprendizagemensino e entre os sujeitos que lhe dão vida, para oferecer conhecimentos necessários à realização do trabalho escolar.

A classificação do desempenho infantil como mobilizador da avaliação rompe essas conexões. Nesse sentido, é importante um breve olhar para o cotidiano escolar para recolher alguns indícios de como a avaliação externa impacta suas práticas. Diante da padronização que sustenta o processo, mostra-se especialmente relevante pensar sobre como se trata a diferença de percursos e resultados na escola.

Observamos uma tendência crescente de retomada de práticas pedagógicas, no processo de alfabetização, que se prestem mais facilmente ao treinamento e à reprodução, descolando os conteúdos escolares das práticas sociais e culturais. Simultaneamente, a avaliação tem suas dimensões de controle e coerção fortalecidas, sendo um importante procedimento para classificar e selecionar os estudantes a partir de um modelo idealizado, abstrato, universal, descontextualizado de desenvolvimento e de aprendizagem, que sustenta uma imagem desvitalizada de criança que aprende.

As práticas cotidianas se entrelaçam a uma rede com tramas cada vez mais finas que vai separando em grupos, turmas, projetos, salas, entre outras denominações, essas crianças das outras que, não respondendo adequadamente aos exercícios propostos, são classificadas, por oposição às primeiras, como crianças com dificuldade de aprendizagem. A Provinha Brasil, como as outras avaliações estandardizadas em larga escala, se constitui em uma trama discursiva que produz rígidas normas e institui a necessidade de constante normalização.

Incrementa-se a dificuldade de observação e compreensão das múltiplas culturas e experiências individuais, sociais e históricas que tecem o cotidiano escolar e fazem emergir infâncias plurais que interpelam o que, por que, para que e a quem ensinamos, em um diálogo intenso com as aprendizagens que se efetivam na escola. A estrutura que norteia o trabalho retira a legitimidade desses movimentos e trata as diferenças como falta, inferioridade, ou como patologia. Um desvio que precisa voltar ao percurso escolar "normal", parte de um discurso ancorado em processos, nem sempre sutis, de discriminação e segregação.

A padronização tende a capturar as ações escolares cotidianas, invisibilizar as crianças - seus saberes, indagações e processos -, silenciar as dissonâncias que podem desvirtuar o que se apresenta como o método para se atingir o desempenho estipulado como satisfatório. Esse movimento afasta o ensino da aprendizagem e resulta, muitas vezes, na impossibilidade de encontro de caminhos mais potentes que se produzem nas relações que cotidianamente se estabelecem na escola.

Porém, os encontros que a escola favorece engendram potência, que também mantém articulações divergentes do projeto hegemônico e criam oportunidades para outras práticas. Consideramos ser necessária outra avaliação, para ser possível investir maior atenção em processos escolares mais criativos, desafiadores, para que as crianças se apropriem da leitura e da escrita como prática social em que se produzem diálogos e sentidos que convidam à aprendizagem, como ato ininterrupto, como parte do estar no mundo.

\section{Referências}

Esteban, M.T. (2009) Provinha Brasil: desempenho escolar e discursos normativos sobre a infância. Sísifo - Revista de Ciências da Educação, v. 9, p. 47-56.

Hoffmann, J. (2005) Avaliação formativa ou avaliação mediadora? Porto Alegre: Mediação.

Instituto Nacional de Estudos e Pesquisas Educacionais Anísio Teixeira. $<$ http://provabrasil.inep.gov.br/aneb-e-anresc $>$ Acesso em maio de 2015.

Provinha Brasil - Guia de Correção e de interpretação de resultados. Disponível em $<$ http://portal.inep.gov.br/web/provinha-

brasil/edicoes-anteriores $>$ Acesso em 20 de maio de 2015.

Luckesi, C. C. (2005) Avaliação da aprendizagem escolar: estudos e proposições. São Paulo: Cortez. $16^{\text {a }}$ Ed.

Mortatti, M. R. L. Alfabetização no Brasil: conjecturas sobre as relações entre políticas públicas e seus sujeitos privados. Revista Brasileira de Educação v. 15 n. 44 maio/ago. 2010, p. 331

Saul, A. M. (1991) Avaliação emancipatória. São Paulo: Cortez. $2^{\mathrm{a}}$ ed.

Wolf, C. C. (2015) Provinha Brasil no municipio de Niterói: uma discussão sobre avaliação e concepções de aprendizagem na alfabetização (Monografia de Especialização) Universidade Federal Fluminense, Niterói. 